\title{
ASSISTENCIA DE ENFERMAGEM NA TERAPIA ANTIMICROBIANA
}

\author{
Maria Goretti Angarten* \\ Catarina Osawa**
}

ANGARTEN, M. G. \& OSAWA, C. Assistência de enfermagem na terapia antimicrobiana. Rev. Esc. Enf. USP, São Paulo, 15(1):49-53, 1981.

$O$ trabalho tem como objetivo informar sobre alguns conceitos práticos $e$ discorrer sobre cuidados de enfermagem, na administração de quimioterapia antimicrobiana.

As autoras referem os problemas encontrados na administração de associações de antibióticos e recomendam cuidados especiais de enfermagem na terapia antimicrobiana.

\section{Considerações gerais sobre antibióticos e quimioterápicos}

Para a elaboração deste trabalho fez-se necessário conceituar antibióticos e quimioterápicos.

Antibióticos são substâncias químicas produzidas por várias espécies de microrganismos (bactérias, fungos, actinomicetos), que suprimem o desenvolvimento de outros microrganismos e podem também destrui-los (WEINSTEIN ${ }^{11}$ ).

Quimioterápicos são substâncias sintetizadas unicamente em laboratório sem a participação de seres vivos $\left(\operatorname{LOPES}^{6}\right)$.

\section{Classificação dos antibióticos e quimioterápicos}

Os antibióticos e os quimioterápicos podem ser classificados de acordo com diversos critérios (NEUMAN ${ }^{7}$ ): tipo de ação, espectro de ação, origem, local de ação, composição química e carga elétrica (natureza elétrica).

Neste trabalho utilizam-se para a classificação dos antibióticos os critérios que levam em conta o espectro e o tipo de ação.

O espectro de ação representa a gama dos agentes patogênicos sensiveis ao antibiótico considerado. Tem-se assim, antibióticos de espectro muito amplo, médio e estreito. Quanto ao espectro de ação ( $\mathrm{DELIEE}^{3}$ ), o quadro I facilita a indicação de antibióticos e quimioterápicos antimicrobianos. Tal quadro só tem valor relativo, pois, para muitos germes (estafilococos, bacilos gram negativos), existem em face de diferentes antibióticos, uma porcentagem mais ou menos significativa de cepas resistentes.

Os antibióticos de espectro muito amplo podem ser responsáveis pela disseminação das enterobactérias portadoras de fator $R$ (de resistência).

* Enfermeira Supervisora e Coordenadora do Grupo de Atualizaçāo Cientifica do Hospital Osvaldo Cruz.

** Enfermeira da Unidade de Terapia Intensiva do Hospital Osvaldo Cruz. 
(DELIEE ${ }^{3}$ ): Distribuiçāo dos antibióticos e quimioterápicos segundo o organismo provável e o local da infecção.

\begin{tabular}{|c|c|c|}
\hline Infecçäo & Oragnismo provável & Antibióticos \\
\hline $\begin{array}{l}\text { Pele e tecido } \\
\text { subcutâneo }\end{array}$ & $\begin{array}{l}\text { Staphylococcus sp } \\
\text { Streptococcus sp }\end{array}$ & $\begin{array}{l}\text { penicilinas } \\
\text { penicilina G }\end{array}$ \\
\hline Trato urinário & $\begin{array}{l}\text { Escherichia coli } \\
\text { Aerobacter sp } \\
\text { Proteus sp } \\
\text { enterococos }\end{array}$ & $\begin{array}{l}\text { sulfonamidas, ampicilina, te- } \\
\text { traciclinas ou aminoglicosi- } \\
\text { deos, conf. sensibilidade. }\end{array}$ \\
\hline Ouvido (otite média) & $\begin{array}{l}\text { Pneumococcus sp } \\
\text { Haemophylus influenzae } \\
\text { Streptococcus sp }\end{array}$ & $\begin{array}{l}\text { penicilina } G \\
\text { ou } \\
\text { ampicilina }\end{array}$ \\
\hline Trato respiratório & $\begin{array}{l}\text { Pneumococcus sp } \\
\text { Haemophilus influenzae } \\
\text { Escherichia coli } \\
\text { Klebsiella sp } \\
\text { Staphylococcus sp } \\
\text { Mycoplasma }\end{array}$ & $\begin{array}{l}\text { penicilina } G \\
\text { ampicilina } \\
\text { ampicilina e kanamicina } \\
\text { kanamicina e cefalotina } \\
\text { penicilina } \\
\text { eritromicina }\end{array}$ \\
\hline Septicemia & $\begin{array}{l}\text { Staphylococcus sp } \\
\text { Escherichia coli } \\
\text { Pseudomonas sp }\end{array}$ & $\begin{array}{l}\text { penicilina } \\
\text { ampicilina } \\
\text { gentamicina ou kanamicina }\end{array}$ \\
\hline
\end{tabular}

Pode-se dizer que um dos critérios mais úteis de classificação dos antibióticos é aquele que se refere ao tipo de ação. Segundo tal critério, estão assim subdivididos (AMATO NETO ${ }^{2}$ ):

a) Bacteriostáticos: Determinam apenas inibição do crescimento e, conseqüentemente, da multiplicação do agente infeccioso. Fazem parte dessa classe os seguintes grupos de antibióticos: penicilinas, cefalosporinas, aminoglicosídeos, vancomicina, polimixinas e fosfomicina.

b) Bactericidas: Determinam a morte do agente infeccioso e os seguintes grupos fazem parte dessa classe: tetraciclinas, cloranfenicol, eritromicina, lincomicina, clindamicina e rifamicinas.

Para a escolha do antibiótico, vários critérios são utilizadios. Quando não há ainda diagnóstico confirmado, mas há presença de determinadas infeç̧ões em que já se conhecem os agentes etiológicos mais prováveis e o paciente exige uma terapia imediata, o uso de tabelas semelhantes às do Quadro I para a escolha diesses fármacos se impõe. Após a colheita do material para cultura e antibiograma e, enquanto se espera o resultado, é iniciada terapia baseada no combate ao organismo provável. Uma vez conhecido o resultado do antibiograma é aplicad'a a terapia específica e/ou adequada.

\section{Associação de antibióticos}

Podem ocorrer reações indesejáveis entre dois ou mais componentes de uma solução para perfusão; pode ser verificada uma das seguintes incompatibilidades $\left(\right.$ NEUMAN ${ }^{10}$ ):

1) física, que conduz a uma visível mudança na mistura, podendo esta tomar o aspecto de um precipitado, de uma turvação ou ainda ter sua coloração alterada; 
2) química, na qual mudança visível não ocorre necessariamente, mas há modificação das propriedades dos componentes;

3) farmacológica, em que ocorre a potencialização ou diminuição do efeito terapêutico.

Os mecanismos de tais incompatibilidades são múltiplas, visto que há:

— soluções fotossensiveis,

- solventes que podem ser inadequados,

- solutos instáveis em soluções,

- medicamentos que são inativados ou precipitados por interação direta,

- agentes conservantes de uma solução que podem inativar um segundo medicamento,

- medicamentos que fixam o movimento de outro,

- medicamentos que sofrem foto-oxidação,

— interações de natureza ácido-básica.

Quando há necessidade da utilização de dois ou mais antibióticos, é preciso considerar que podem ocorrer interações entre elas. Como regra geral, deve ser lembrado que dois bacteriostáticos têm ação indiferente; dois bactericidas, ação sinérgica e um bactericida com um bateriostático, ação antagônica.

$\mathrm{Na}$ associação indiferente ou adiliva, não há interação entre os componentes, exercendo cada antibiótico sua atividade como se atuasse isoladamente. A associação é sinérgica quando dela resulta um efeito claramente benéfico, caracterizado pela potencialização do efeito esperado de pelo menos um dos antimicrobianos; a resultante final é muito maior do que a simples soma dos efeitos esperados de cala um dos componentes da associação. $\mathrm{Na}$ associação antagônica, o efeito obtido é menor do que a soma dos efeitos de cada um dos antibióticos associados, o que significa que o uso isolado do antibiótico mais ativo seria mais eficaz.

Como inconvenientes da associação de antibióticos citam-se os seguintes: alto custo, ef eitos adversos, superinfecção, incompatibilidade física ou química e antagonismo.

Para o uso correto de associações de antibióticos existem preceitos básicos; como exemplo resumimos as principais recomendações de AMATO NETO 2:

1) não empregá-las sem respeitar as indicações específicas referidas;

2) efetuar o diagnóstico etiológico antes de iniciar o tratamento;

3) fazer, sempre que possivel, testes de sensibilidade "in vitro" com as diversas associações;

4) preferir a combinação de antibióticos bactericidas ao fazer uma associação; 
5) evitar o emprego de bactericida com bacteriostático, pois mostram-se com freqüência antagônicos;

6) evitar as associações que não evidenciem nítido aumento do espectro antimicrobiano ao ser efetuado o tratamento de quadros graves, sem diagnóstico etiológico;

7) evitar o emprego de associação de antibióticos que apresentem efeitos adversos coincidentes;

8) conservar nas associações as mesmas doses dos antibióticos que se usam quando prescritos isoladamente, $\mathrm{e}$

9) não empregar associações de antibióticos cuja apresentação comercial já contenha alguma associação.

\section{Assistência de enfermagem na terapia antimicrobiana}

A administração de toda medicação, inclusive de antibióticos, é feita por pessoal de enfermagem. É de suma importância que o enfermeiro tenha conhecimentos teóricos acerca destes fármacos, para que possa orientar o pessoal que vai administrá-los, a fim de que os seguintes cuidados sejam observados:

1. Procurar na bula que acompanha o medicamento as principais orientações sobre precauções, modo de preparo, administração e estabilidade da solução.

2. Não fazer associação de medicamentos na mesma seringa para aplicação única, devido à possibilidade de ocorrência de uma das interações indesejáveis anteriormente citadas.

3. Efetuar a diluição do liofilizado com o diluente que o acompanha e, na sua falta, fazê-lo com água bidestilada, salvo indicação em contrário na bula.

4. Regular os horários das aplicą̧ões. Os antibióticos habitualmente ministrados pela via E.V. e que têm a sua via modificada para V.O. ou I.M. deverão ter seus horários antecipados, para que o nível sérico seja mantido.

5. Verificar a duração do tratamento pois esta não deve ser inferior a sete dias ou superior a dez dias, devido aos efeitos tóxicos da droga $\left(\operatorname{LEE}^{5}\right)$, e também porque há interferência na eficácia do antibiótico, podendo ocorrer aumento da sensibilidade do paciente e diminuição do microrganismo à droga.

6. Verificar, no caso de administração por V.O., qual o veículo e se é em horário de refeição, pois a absorção é mais demorada se a ingestão ocorre em estado de plenitude gástrica ou associada a antiácidos (LAMBERT ${ }^{4,8,9}$ ), e mais rápida quando associada ao leite (transporte ativo por lipídios), exceto no caso das tetraciclinas cuja interação com leite e produtos lácteos tem efeito contrário.

A terapia antimicrobiana pode ser tornada ineficaz em casos como:

- administração de antibióticos vencidos e conservados em local e condições inadequadas, 
- substituição de antibióticos por simulares não exatos, e

- mudança de leito do paciente sem a respectiva aleração na disribuição dos medicamentos.

IV. Efeitos colaterais dos antibióticos e ação da enfermagem

Existem efeitos colaterais dos antibióticos que podem ser minimizados pela intervenção da equipe de enfermagem.

Assim, antibióticos administrados por V.O. poderão provocar náuseas, vômitos, dor gástrica e diarréia. Medidas para prevenção ou melhora podem ser tomadas, sob orientação médica.

No local da aplicação de antibióticos pela via I.M. poderá ocorrer endurecimento e dor. Recomendam-se compressas quentes, massagem e aplicação do antibiótico em locais alternados.

A aplicação por via E.V. poderá provocar dor, flebite ou esclerose do vaso, principalmente se este for periférico. A mudança do local da punção e a observação constante e cuidadosa dos sinais e sintomas de complicação são medidas a serem adotadas para a prevenção de danos irreversíveis.

ARGARTEN, M. G. \& OSAWA, C. Antibiotics and chemotherapy nursing care. Rev. Esc. Enf. USP, São Paulo, 15(1):49-53, 1981.

The authors describe treatment by antibiotics and chemotherapy including the possible sffects of drug association. They also emphasize the nursing care to be given to patients under treatment with such drugs.

\section{REFERENCIAS BIBLIOGRAFICAS}

1. AMATO NETO, V. et alii. Associação de antibióticos. In: médica. São Paulo, Gremed, 1978. p. 201-18.

2. — Efeitos adversos dos antibióticos. Ibid. p. 41-64.

3. DELIEE, S. \& CARDONI, A. A. Team effort keep wonder drugs wonderfull. Nursing, Jenkinton, 5(1): 22-7, Jan. 1975 .

4. LAMBERT JUNIOR, M. L. Drug and diet interactions. Amer. J. Nurs., New York, 75(3): 402-6, Mar. 1975.

5. LEE, R. V. Antimicrobial therapy. Amer. J. Nurs., New York, 73(12): 2044-8, Dec. 1973.

6. LOPES, H. V. Antibióticos e antibioticoterapia. In: VERONESI, $R$, et alii. Doenças transmissíveis e parasitárias. 6. ed. Rio de Janeiro, Guanabara Koogan, 1976. p. 984-1031.

7. NEUMAN, M. Classificação dos antibióticos. In: Vade-mecum dos antibióticos o agentes quimioterápicos anti-infecclosos. 4. ed. São Paulo, Andrei, 1978. p. 7-18.

8. —_ Farmacologia clínica ods antibióticos. Ibid. p. 19-50.

9. —uterações ao nivel da absorção digestiva. In: — Guia das interações medicamentosas e repertório dos medicamentos por classes terapêuticas. São Paulo, Andrei, 1978. p. 11-7.

10. 1978. p. Interações diretas das soluções de međicamentos injetáveis na mistura đos solutos em perfusão. Ibid. p. 73-99.

11. WEINSTEIN, L. Chemotherapy of microbial diseases. In: GOODMAN, L. S. \& GILMAN, A. The pharmacological basis of the therapeutics. 4. ed. New York, Macmillan, 1970. p. 1154-76. 